\title{
Elaboração de aplicativos para Android com uso do App Inventor: uma experiência no Instituto Federal do Paraná - Câmpus Irati
}

\begin{abstract}
Rodrigo Duda
Sani de Carvalho Rutz da Silva

Diego Dutra Zontini

Luciane Grossi

Resumo

Neste trabalho apresentamos resultados parciais de um projeto de extensão executado no Câmpus Irati do Instituto Federal do Paraná. Tendo como objetivos principais o desenvolvimento do pensamento algébrico dos alunos participantes e a exploração das potencialidades do App Inventor, designer de aplicativos gerenciado pelo Instituto de Tecnologia de Massachusetts, na elaboração de aplicativos para execução de cálculos, o projeto visa também a elaboração de materiais que possam contribuir para a melhoria na prática docente em matemática. $O$ trabalho se refere à análise qualitativa de dados coletados durante a execução das atividades iniciais do projeto, realizadas durante os meses de abril a julho de 2014. Por meio das atividades desenvolvidas foi possível verificar a possibilidade de utilização das atividades decorrentes do processo de elaboração dos aplicativos como objetos auxiliares no processo de avaliação em matemática, no desenvolvimento da autonomia discente e na forma de estruturar logicamente o pensamento.
\end{abstract}

Palavras-chave: ensino de matemática, aplicativos, App Inventor.

\begin{abstract}
Developing of applications for android using app inventor: an experience at Campus Irati of the Federal Institute of Paraná

This paper presents partial results of an extension project executed at Campus Irati of the Federal Institute of Paraná. Having as its main goals the development of algebraic thought of participating students and the exploiting of the App Inventor potential, designer of applications managed by Massachusetts Institute of Technology, in designing applications to run calculations, the project also aims at developing materials that can contribute to improvement in the teaching practice of mathematics. The paper refers to the qualitative analysis of data collected during the execution of the initial project activities, conducted from April to July 2014. Through the activities developed it was possible to verify the possibility of using the activities resulting from the preparation of applications as auxiliary objects in the process of mathematics evaluation, in the development of student autonomy and how to structure the thinking logically.
\end{abstract}

Keywords: mathematics teaching, applications, App Inventor. 


\section{Introdução}

Diante da avalanche de informações à disposição do aluno e da rapidez com que a tecnologia tem se tornado cada vez mais presente na vida dos educandos, um dos desafios impostos aos docentes é como aproveitar essas ferramentas tecnológicas a favor do ensino. Compreender como os recursos computacionais podem contribuir para o desempenho das ações humanas e ser capaz de explorar programas de computadores e seus componentes são requisitos mínimos que os alunos devem dominar, correspondendo às exigências do atual mundo do trabalho (COX, 2003).

Em particular, com relação à utilidade dos computadores no âmbito do desenvolvimento de projetos de pesquisa, pode-se destacar a importância da exposição dos resultados obtidos pelos alunos nos estudos realizados. A valorização do trabalho discente, bem como o fato de poder divulgar resultados de estudos realizados à comunidade, pode despertar ainda mais o interesse pela pesquisa (COX, 2003).

Com esses pressupostos, o presente trabalho visa apresentar resultados parciais das atividades desenvolvidas no projeto de extensão "Desenvolvimento de aplicativos para dispositivos com sistema operacional Android com uso do App Inventor", executado no Câmpus Irati do Instituto Federal do Paraná (IFPR). Além de inserir os discentes do Câmpus Irati em atividades de pesquisa e extensão, o projeto visou explorar as potencialidades do App Inventor e desenvolver atividades e materiais que eventualmente possam ser utilizados por docentes da área de matemática em suas aulas.

$\mathrm{Na}$ estruturação das atividades do projeto se objetivou a abordagem do uso da representação algébrica na solução de problemas relacionados aos temas estudados, com o intuito de desenvolver o pensamento algébrico dos discentes envolvidos.

Objetivou-se, também, desenvolver a autonomia dos discentes com relação à busca por informações que auxiliem no processo de elaboração dos aplicativos, resultando, consequentemente, no domínio acerca dos temas matemáticos abordados nas atividades.

\section{Tecnologia e Ensino de Matemática}

Uma alternativa viável para diversificação das estratégias docentes é a utilização de ferramentas tecnológicas em sala de aula, em especial, com relação ao uso de computadores. A alfabetização informática deve ser considerada como algo tão importante quanto a alfabetização na língua materna e em matemática (BORBA e PENTEADO, 2012).

Por ser uma ferramenta que se torna cada vez mais frequente na vida dos educandos, sua utilização pode englobar tanto a pesquisa acerca da temática estudada, quanto a utilização de 
softwares educacionais ou de execução de cálculos, constituindo-se num grande leque de possibilidades à disposição do professor.

Domesticar uma mídia e utilizá-la em prol da aprendizagem se torna um desafio tão grande quanto contextualizar conteúdos estudados com o cotidiano discente. Dentre as barreiras que podem influenciar no sucesso/fracasso de atividades envolvendo recursos computacionais, podemos citar a resistência docente a rever suas estratégias e a falta de preparo técnico para realizar esse tipo de atividade. Esse tipo de mudança afeta a zona de conforto do professor, criando uma zona de risco, com baixo índice e certeza e controle da situação (PENTEADO, 2000).

Ressalte-se também a importância da preparação do professor com relação ao uso das tecnologias e as transformações que essa prática pode ocasionar na função do professor em sala de aula. Uma vez que o professor é o responsável direto pelo uso do computador no ambiente escolar, as possibilidades de trabalho dependerão do seu desempenho (GRACIAS, 2000).

Outro fator que impõe limite à possibilidade de planejar atividades desse cunho é a falta de estrutura no ambiente escolar. Nesse contexto, torna-se necessário o uso de um laboratório de informática adequado, equipado com computadores em número suficiente para o grupo de alunos envolvidos e que possuam configurações mínimas para que as atividades idealizadas sejam realizadas a contento.

Antes dos recursos computacionais serem efetivamente inseridos no ambiente educacional, é necessário refletir se essa inserção contribuirá para a melhoria da qualidade das atividades desenvolvidas, sendo necessário avaliar cuidadosamente a viabilidade de sua inserção em sala de aula (COX, 2003).

Os objetivos e competências a serem adquiridas pelos estudantes devem ser considerados no momento de escolher e introduzir uma ferramenta tecnológica nas atividades a serem desenvolvidas. Caso contrário, é possível que a ferramenta escolhida não seja integrada ao processo de ensino e aprendizagem, sendo apenas um simples adereço (GIRALDO, CAETANO e MATTOS, 2013).

Quanto à forma de estruturar as atividades, recomendam-se propostas pedagógicas que enfatizem a experimentação, visualização, simulação, comunicação eletrônica e problemas abertos como uma forma de estar em sinergia com a informática (BORBA e PENTEADO, 2012).

Diante dos desafios aqui elencados, o docente deve estar em constante processo de atualização, buscando aprimorar-se quanto ao uso da tecnologia da informação nas atividades em sala, aproveitando-a da melhor forma no planejamento das atividades de ensino. 


\section{Sobre o projeto de extensão}

Criados em 2008 pela Lei no 11.892, os Institutos Federais de Educação tem como uma de suas finalidades o desenvolvimento de programas de extensão e de divulgação científica e tecnológica (BRASIL, 2008).

Dentro das ações institucionais de apoio à extensão no âmbito do Instituto Federal do Paraná, o apoio financeiro ao desenvolvimento de atividades desse cunho é realizado mediante programas específicos, disponibilizando recursos a projetos que atendam a critérios pré-definidos e que estejam em consonância com a política institucional de indissociabilidade das atividades de ensino, pesquisa e extensão.

Nesse cenário, o projeto de extensão "Desenvolvimento de aplicativos para dispositivos com sistema operacional Android com uso do App Inventor" foi concebido, tendo como objetivos principais a inserção de discentes do Câmpus Irati em pesquisa e extensão e a exploração do potencial do App Inventor, designer de aplicativos do MIT (Massachusetts Institute of Technology), na elaboração de aplicativos para execução de cálculos para uso em dispositivos móveis que operam com o sistema operacional Android.

O projeto foi contemplado com recursos provenientes do Edital no 01/2014 PROEPI/IFPR, referente ao Programa de Bolsas de Extensão do IFPR, recebendo apoio financeiro para aquisição de materiais necessários para sua execução, bem como a disponibilização de bolsas de extensão para três alunos, com vigência nos meses de abril a dezembro de 2014.

O projeto contou ainda com a colaboração de um bolsista contemplado via Edital $\mathrm{n}$ ㅇ 03/2014 - PROENS/IFPR, referente ao Programa de Bolsas Acadêmicas de Inclusão Social. O aluno ingressou no projeto no mês de maio. Porém, destaque-se que o bolsista atuou como voluntário no projeto desde o mês de abril de 2014.

Além dos bolsistas vinculados aos programas institucionais de apoio à extensão e inclusão social, o projeto contou com a colaboração de um aluno que atuou como voluntário no desenvolvimento das atividades, também atuante desde o mês de abril de 2014.

\section{Metodologia}

As mídias digitais se tornam interessantes quando auxiliam a mudar a dinâmica da sala de aula, valorizando o desenvolvimento de habilidades cognitivas concomitantemente com a aprendizagem da Matemática (GRAVINA e BASSO, 2012). Leva-se em conta ainda que o uso das

TICS pode ter diferentes finalidades, como fonte de informação, auxiliar no processo de construção de conhecimentos ou como meio para desenvolver autonomia pelo uso de softwares que possibilitem pensar e criar soluções (GARCIA, 2012).

118 DOI: Em andamento.

R. Bras. de Ensino de C\&T 
Com esses pressupostos, as atividades envolvendo a criação de aplicativos foram estruturadas de forma que os discentes participantes sejam sujeitos ativos em sua aprendizagem, tornando-se independentes na realização das pesquisas, ampliando seu conhecimento acerca das temáticas abordadas e compartilhando com os demais colegas o conhecimento adquirido. Nesse sentido, buscou-se mesclar o uso da lógica, entremeada na arquitetura e estruturação dos aplicativos, com a linguagem matemática utilizada na representação dos resultados, atividades que exigem ainda de criatividade e autonomia.

Desta forma, os aplicativos desenvolvidos pelos alunos não são a essência do projeto de extensão, mas também a verificação do potencial e influência das pesquisas e estudos acerca dos temas abordados no desenvolvimento do uso de linguagem matemática para a modelagem e escrita de soluções de problemas, no desenvolvimento do pensamento algébrico e da autonomia discente na busca por informações.

No contexto de desenvolvimento do pensamento algébrico, torna-se necessário ainda o senso de organização para a estruturação dos componentes visuais e lógicos dos aplicativos desenvolvidos. Desta forma, as atividades foram estruturadas em etapas interligadas, nas quais são elencados os conhecimentos necessários para a elaboração do aplicativo, dentre outras características relevantes para sua estruturação, conforme descrito a seguir:

Etapa 1 - Pesquisa: os temas são apresentados aos bolsistas, os quais devem elaborar pesquisas sobre o tema apresentado, culminando em uma síntese contendo os pontos-chave acerca do objeto estudado. Nessa etapa, o professor indica qual é o foco da pesquisa e o objeto a ser pesquisado, apresentando também referências para nortear o trabalho dos alunos;

Etapa 2 - Arquitetura: etapa na qual os temas pesquisados são aplicados na estruturação dos aplicativos, resultando em um software para execução de cálculos;

Etapa 3 - Revisão: etapa na qual o professor orientador verifica possíveis falhas ou erros na execução dos cálculos, apontando onde e como o aplicativo pode ser corrigido ou adaptado. Nesse momento é possível constatar se os pontos elencados na síntese foram efetivamente utilizados na elaboração do aplicativo, ou se foram simplesmente listados, sem a preocupação acerca de sua compreensão;

Etapa 4 - Consolidação: etapa na qual os aplicativos são validados com relação à sua estruturação e funcionalidades.

Cabe enfatizar que para estruturar os aplicativos no App Inventor não há a necessidade de prévio conhecimento sobre linguagem de programação, pois as funções dos elementos necessários para os aplicativos são pré-dispostos no designer de aplicativos na forma de blocos lógicos, que podem ser justapostos para gerar as funções necessárias. 
Ao final da elaboração de cada aplicativo, os bolsistas apresentaram um tutorial a respeito de como o mesmo foi elaborado. Por meio desse instrumento é possível verificar se os conceitos matemáticos pesquisados foram utilizados de forma adequada, bem como foram incorporadas as ferramentas necessárias para o funcionamento do aplicativo, sendo possível ainda detectar eventuais erros lógicos que possam surgir na representação dos resultados.

Salienta-se que a escolha dos temas abordados para realização das atividades foi feita baseando-se numa sequência crescente de complexidade, abordando inicialmente a relação entre grandezas proporcionais, com posterior abordagem de algoritmos e relações algébricas que exigem uma análise mais complexa dos conceitos matemáticos envolvidos e um nível maior de abstração.

\section{Resultados e Discussão}

A seguir, apresentamos como alguns dos aplicativos foram concebidos, a forma como foram conduzidos os trabalhos e observações a respeito dos obstáculos enfrentados para sua efetivação durante as atividades desenvolvidas nos meses de abril a julho de 2014.

Por questões éticas, os alunos participantes das atividades aqui foram nomeados como A1, A2, A3, A4 e A5, levando-se em consideração a ordem alfabética de seus nomes.

\section{Aplicativo 1 - Resolução de regra de três com grandezas diretamente proporcionais}

Este aplicativo foi desenvolvido na etapa inicial do projeto de extensão, na qual os bolsistas atuantes no processo tiveram seu primeiro contato com o App Inventor. Optou-se por tomar esse modelo matemático simples por se tratar do contato inicial dos discentes com a ferramenta de desenvolvimento de aplicativos e por apresentar solução algébrica de fácil entendimento.

Por se tratar também do momento introdutório com relação à metodologia do projeto, a Etapa 1 não foi executada. No entanto, foram discutidos aspectos relevantes referentes à forma do trabalho a ser executado, principalmente com relação à sintetização das ideias e da necessidade de representar algebricamente a solução de um problema.

Diante da necessidade de estruturar os aplicativos com riqueza de detalhes e funcionalidades, foram apresentados aos alunos os seguintes questionamentos:

- Onde o usuário deve inserir os dados para o cálculo?

- Como será ativada a resolução?

- Onde será representada a resposta do problema?

- Como será fechado o aplicativo? 
- E se o usuário necessitar efetuar outro cálculo, como reiniciar o processo?

As respostas a esses questionamentos se tornam úteis devido à necessidade da estruturação adequada dos campos de entrada e saída de dados e ativação de comandos. Embora mentalmente seja relativamente simples idealizar como o aplicativo executará os passos para a solução, organizá-los sistematicamente auxilia no momento de escolher as ferramentas adequadas que o tornem funcional.

Para o desenvolvimento do aplicativo para resolução de regras de três simples foi analisada a forma como se relacionam os elementos envolvidos na resolução de uma regra de três simples, em particular, na que envolve grandezas diretamente proporcionais, relacionando a estrutura de um sistema comparativo da razão entre grandezas diretamente proporcionais.

Após a resolução de exemplos envolvendo esse tipo de grandezas, os alunos foram estimulados a representar a solução algébrica da regra de três disposta a seguir, onde $x$ representa o valor a ser calculado.

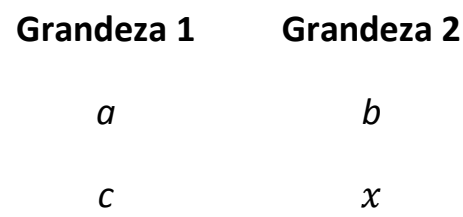

Por meio da solução algébrica da representação, onde $x=\frac{b c}{a}$, partiu-se para a elaboração do aplicativo para resolução de regras de três simples. Após apresentadas as ferramentas básicas do App Inventor, os alunos foram estimulados a criar o design de seus aplicativos. Transcorrida essa etapa, foi trabalhada a forma de inserir os comandos lógicos para a execução dos cálculos.

$\mathrm{Na}$ atividade de desenvolvimento do aplicativo relacionado ao tema foi possível verificar particularidades na forma de trabalho de cada aluno envolvido, como a escolha das cores utilizadas e as formas de organizar as telas e os campos para entrada e saída de dados, conforme disposto nas figuras 1 a 5 .

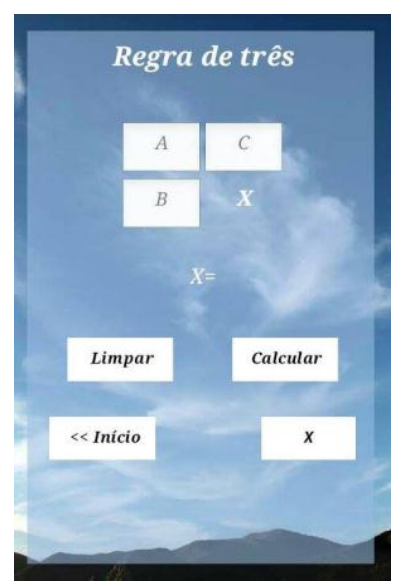

Figura 1 - Tela de cálculo do aplicativo elaborado pelo aluno A1 


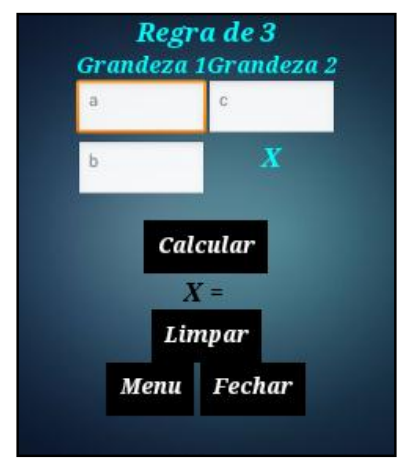

Figura 2 - Tela de cálculo do aplicativo elaborado pelo aluno A2

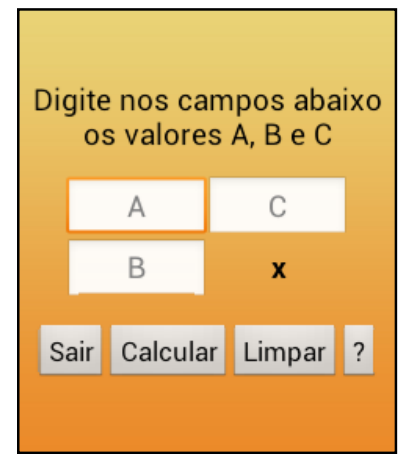

Figura 3 - Tela de cálculo do aplicativo elaborado pelo aluno A3

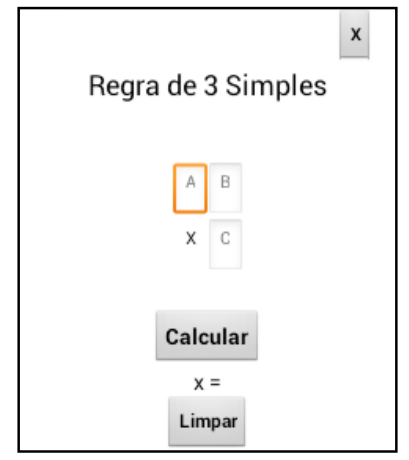

Figura 4 - Tela de cálculo do aplicativo elaborado pelo aluno A4

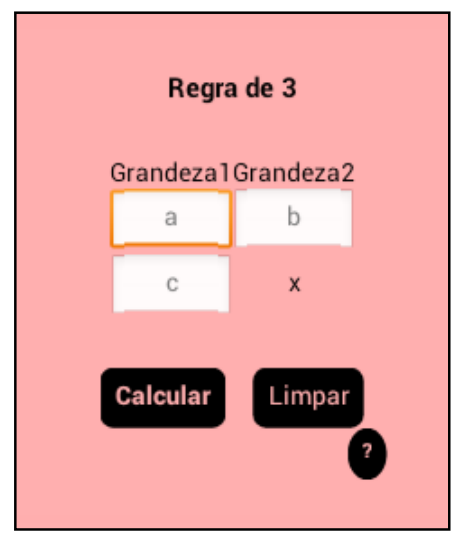

Figura 5 - Tela de cálculo do aplicativo elaborado pelo aluno A5 


\section{Aplicativo 2 - Comparação de preços de combustíveis}

Após o surgimento dos carros modelo flex no mercado automobilístico, um dilema surgiu no cotidiano dos motoristas: "Abastecer com etanol ou com gasolina?". Embora existam várias características que devem ser consideradas para essa análise, como o desempenho de cada modelo de veículo com relação ao combustível utilizado, o perfil do motorista ou o trajeto a ser percorrido (na cidade ou em rodovias), uma regra simples é efetivamente mais utilizada, baseada em resultados de testes realizados pelo Instituto Nacional de Metrologia, Qualidade e Tecnologia. Segundo essa regra, o abastecimento com etanol é vantajoso quando o preço do litro do etanol não ultrapassar 70\% do preço do litro da gasolina (BRASIL, 2013).

Com base nessas informações, os alunos foram estimulados a estabelecer relações entre o preço do litro do etanol combustível com o preço da gasolina. Para tal, a informação necessária para efetuar a análise foi apresentada aos alunos, sendo discutido sobre a relação entre as representações $70 \%$ e 0,7 no cálculo de porcentagens e desenvolvidas as atividades elencadas a seguir:

Problema 1 - Segundo o INMETRO, o abastecimento com álcool é vantajoso quando o preço do álcool não ultrapassar $70 \%$ do preço da gasolina. Usando esta informação, verifique qual combustível é o mais vantajoso em cada caso listado a seguir:

a) Preço do litro do álcool: $R \$ 1$ 1,957; preço do litro da gasolina: $R \$ 2,857$;

b) Preço do litro do álcool: $R \$ 2,157$; preço do litro da gasolina: $R \$ 2,997$;

c) Preço do litro do álcool: $R \$ 2,065$; preço do litro da gasolina: $R \$ 2,95$;

d) Preço do litro do álcool: $R \$ 2,105$; preço do litro da gasolina: $R \$ 2,957$.

Problema 2 - Baseando-se na informação inicial sobre a comparação entre o preço do litro do álcool e da gasolina, represente algebricamente as possiveis relações entre os preços dos combustíveis e a análise correspondente.

Para o problema 2, as respostas dos alunos foram apresentadas conforme disposto nas figuras 6 a 10. Cabe ressaltar que os alunos A4 e A5 tiveram que complementar a resposta, pois no primeiro registro haviam informado as relações sem representá-las na forma algébrica.

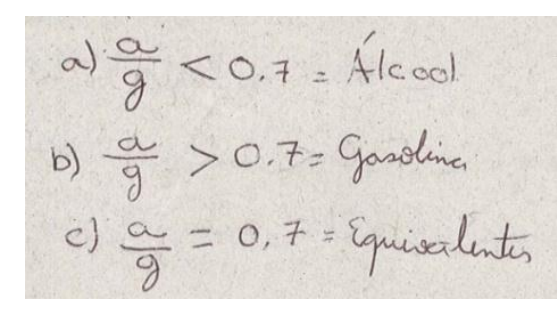

Figura 6-Resposta apresentada pelo aluno A1 


$$
\begin{aligned}
& \frac{A}{G}>0,7 \rightarrow \text { Gasolina } \\
& \frac{A}{G}<0,7 \rightarrow \text { Álcool } \\
& \frac{A}{G}=0,7 \rightarrow \text { Equivalentes }
\end{aligned}
$$

Figura 7-Resposta apresentada pelo aluno A2

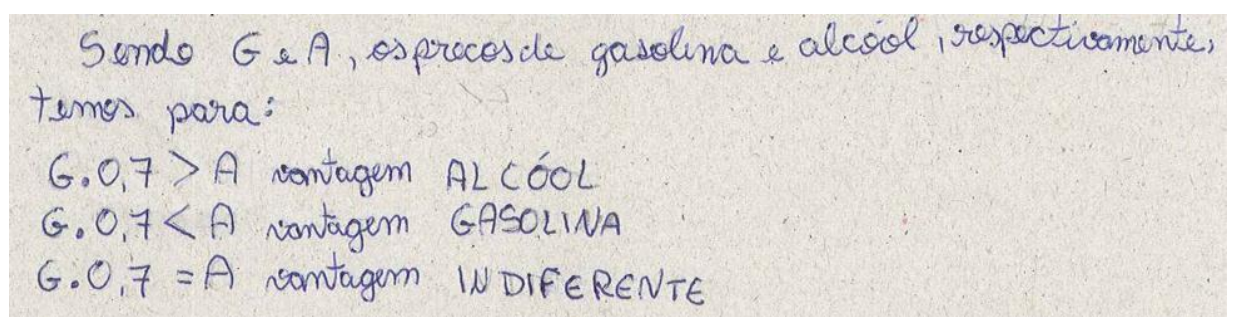

Figura 8-Resposta apresentada pelo aluno A3

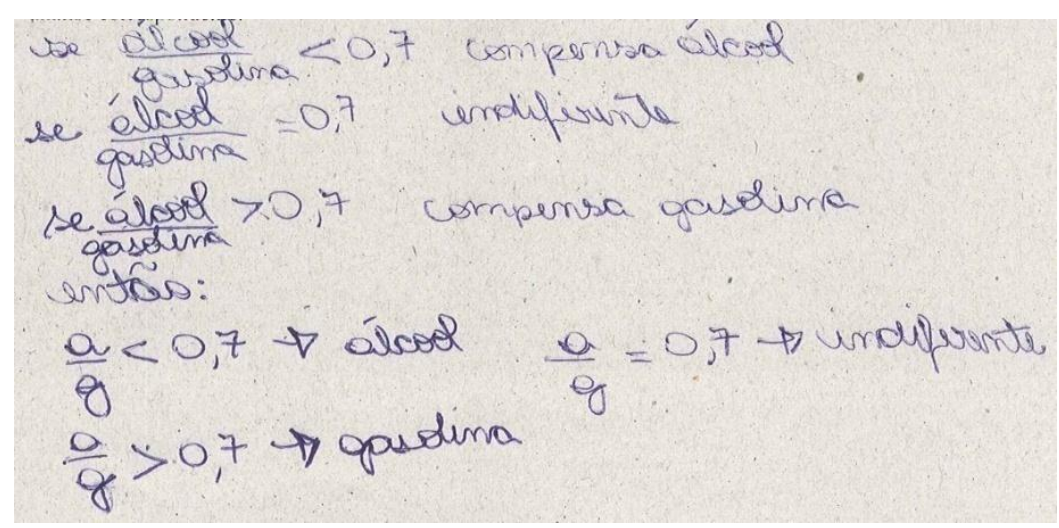

Figura 9-Resposta apresentada pelo aluno A4

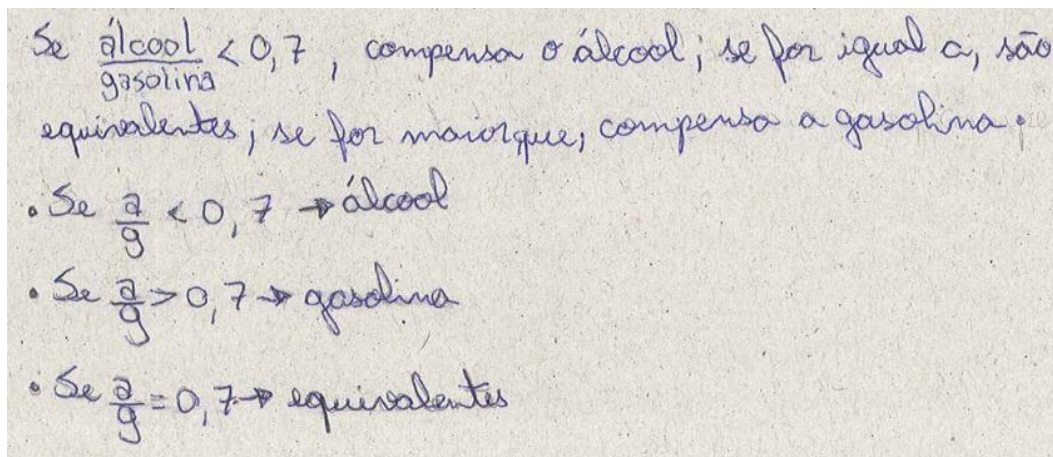

Figura 10 - Resposta apresentada pelo aluno A5

As representações simbólicas são essenciais para a organização do conhecimento escolar (MENDES, 2009). Desta forma, com a atividade proposta objetivou-se não só a resolução do cálculo de porcentagem relacionado aos valores apresentados no problema, mas também sistematizar a situação-problema estudada por meio de linguagem algébrica. 
As representações mentais constituem-se na forma individual que o aluno tem para formular o que foi internalizado sobre a situação matemática. Desta forma, um mesmo conceito matemático pode ter diferentes representações mentais (MENDES, 2009). Corrobora-se isso na solução apresentada pelo aluno A3, conforme ilustrado na Figura 8. Enquanto os demais alunos apresentaram a relação entre o preço dos combustíveis na forma de uma razão, o aluno A3 optou por comparar os preços efetuando o cálculo de $70 \%$ do preço do litro da gasolina, caracterizado pela multiplicação do fator 0,7 pelo valor do preço da gasolina.

A solução do problema 2 foi utilizada pelos alunos para elaborar um aplicativo para comparação entre o preço do litro desses combustíveis, fornecendo a análise ao consumidor no momento de abastecer seu veículo, sendo cada aluno responsável por fazer um aplicativo com tal funcionalidade. Na figura 11 temos as possíveis análises geradas pelo aplicativo elaborado pelo aluno A3.

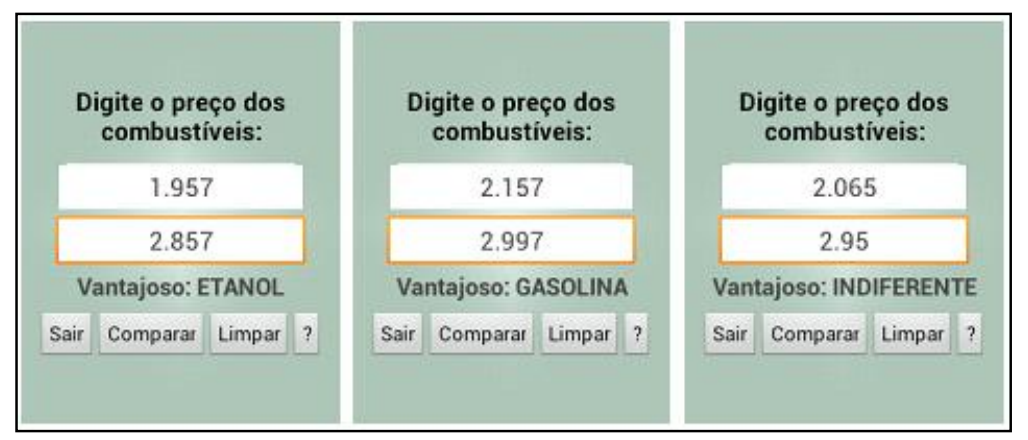

Figura 11 - Possíveis análises do aplicativo desenvolvido pelo aluno A3

\section{Demais aplicativos desenvolvidos}

Nos meses iniciais de execução do projeto, diversos foram os temas e conteúdos matemáticos explorados pelos alunos, resultando em aplicativos cujos resultados são elencados a seguir:

- Aplicativos para resolução de equações e inequações de 10 e 20 graus;

- Aplicativo para resolução de problemas envolvendo o teorema de Pitágoras;

- Aplicativo gerador de ternas pitagóricas;

- Aplicativo para comparação entre o preço de produtos;

- Aplicativo para conversões de câmbio;

- Aplicativo para determinação da lei de formação de uma função afim por meio de dois pontos de seu gráfico.

Sobre os aplicativos desenvolvidos para resolução de inequações e equações, destacamos o Inequa App, desenvolvido pelo aluno A3, conforme ilustrado na Figura 12. 


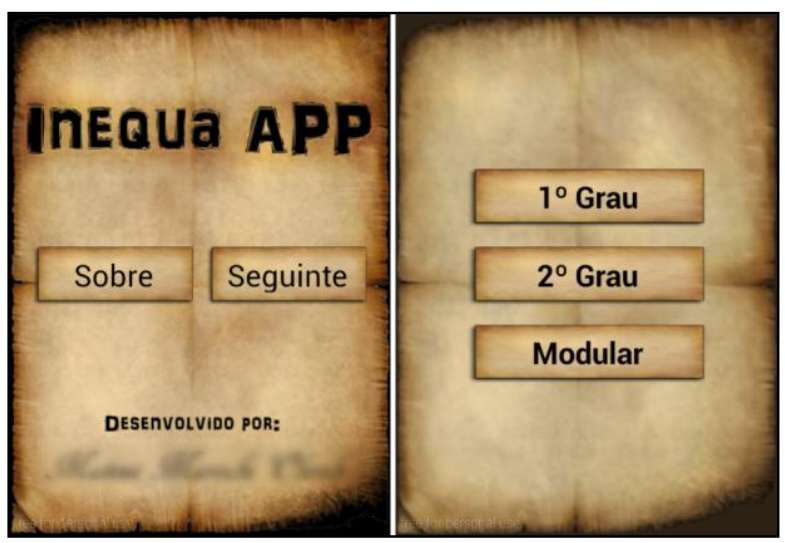

Figura 12 - Telas iniciais do Aplicativo Inequa App

É possível verificar a criatividade e autonomia do aluno com relação à inserção de um plano de fundo estilizado, criado com auxílio de um software específico para a edição e criação de imagens. Como com a adoção de recursos de informática é criado um ambiente dinâmico de aprendizagem, no qual a capacidade de criação dos jovens é desafiada e compelida a desenvolver-se gradativamente, as tarefas ganham cores e imagens que se modificam sob o controle dos educandos, características responsáveis por despertar os alunos do sono da passividade (COX, 2003).

\section{Considerações finais}

Seguindo o cronograma planejado para execução no 2 o semestre letivo de 2014 , ainda foram explorados conceitos relacionados à matemática financeira, estudo de sistemas lineares e aplicações da matemática em outras áreas do conhecimento, em particular, nas disciplinas da grade curricular do curso em que os alunos estão matriculados.

Objetivou-se ainda a criação de um blog contendo um banco de aplicativos desenvolvidos pelos bolsistas, contando também com materiais instrucionais sobre a forma de elaboração de aplicativos de execução de cálculos com o App Inventor, de forma que essas informações possam ser utilizadas pela comunidade escolar e por docentes que objetivem estruturar atividades relacionadas ao uso de recursos computacionais em suas aulas. O foco dessa atividade foi o incentivo à divulgação dos resultados dos trabalhos desenvolvidos pelos alunos, valorizando sua criatividade e empenho. Os materiais produzidos pelos alunos foram disponibilizados no endereço ifdroid-irati.blogspot.com.br.

De modo geral, há que se destacar o potencial que o desenvolvimento dos aplicativos pode representar no processo de ensino e aprendizagem. Mediante a análise dos materiais produzidos pelos bolsistas, percebe-se que a qualidade nos resultados e produtos apresentados é vertiginosamente crescente. Em apenas quatro meses de execução é possível constatar, em alguns momentos, a preocupação de alguns dos bolsistas em apresentar não apenas o aplicativo 
idealizado, mas também apresentar o melhor resultado possível utilizando o tempo e os recursos disponíveis para tal.

O compartilhamento de ideias entre os membros do grupo e a busca por conhecer ferramentas alternativas para utilização na arquitetura dos aplicativos tem sido um ponto de destaque nas atividades desenvolvidas pelos bolsistas. Em diversos momentos foram apresentados layouts de aplicativos contendo ferramentas de design não apresentadas pelo professor orientador, evidenciando que os alunos têm atuado com autonomia no sentido de buscar conhecimento que agregue qualidade ao trabalho desenvolvido.

Embora ainda não tenha sido viabilizada a aplicação dessa dinâmica de ensino na sala de aula convencional, observa-se que o roteiro de estudos e demais produtos decorrentes do processo de elaboração de um aplicativo podem ser utilizados como objetos auxiliares para a avaliação em matemática, possibilitando a análise qualitativa do processo de ensino e aprendizagem no que diz respeito à autonomia do discente em buscar diferentes fontes e formas de solucionar ou descrever um problema, bem como estruturar logicamente o pensamento.

\section{Referências}

BORBA, M. de C.; PENTEADO, M.G. Informática e Educação Matemática. 5. ed. Belo Horizonte: Autêntica, 2012. (Coleção Tendências em Educação Matemática, 2).

BRASIL. Lei no 11.892, de 29 de dezembro de 2008. Institui a Rede Federal de Educação Profissional, Científica e Tecnológica, cria os Institutos Federais de Educação, Ciência e Tecnologia, e dá outras providências. Brasília. 2008. Disponível em: <http://uww.planalto.gov.br/ccivil_03/_ato20072010/2008/lei/111892.htm>. Acesso em: 21 jul. 2014.

BRASIL. Ministério de Minas e Energia. Empresa de Pesquisa Energética. Avaliação do comportamento dos usuários de veículos flex fuel no consumo de combustíveis no Brasil. Brasília. 2013. Disponível em: <http://www.epe.gov.br/petroleo/documents/dpg_docs/epe-dpgsdb-001-2013-r0.pdf>. Acesso em 21 jul. 2014.

COX, K. K. Informática na educação escolar. Campinas: Autores Associados, 2003. (Coleção Polêmicas do nosso tempo, 87).

GARCIA, V.C.V. Formação de professores de matemática e mudanças curriculares na escola. In: BÚRIGO, E.Z., et al. (Orgs.). A Matemática na escola: novos conteúdos, novas abordagens. Porto Alegre: Ed. da UFRGS, 2012. p. 11-23 (Série Educação a distância).

GIRALDO, V; CAETANO, P; MATTOS, F. Recursos Computacionais no Ensino de Matemática. Rio de Janeiro: SBM, 2012. (Coleção PROFMAT, 06). 
GRACIAS, T. S. O projeto de informática na educação - PIE. In: PENTEADO, M.G; BORBA, M. de C. (Orgs.). A informática em ação: formação de professores, pesquisa e extensão. São Paulo: Olho d’Água, 2000. p. 9-22.

GRAVINA, M. A.; BASSO, M. V. de A. Mídias digitais na Educação Matemática. In: GRAVINA, et al. (Orgs.) Matemática, Mídias Digitais e Didática: tripé para formação do professor de Matemática. Porto Alegre: Evangraf, 2012. p. 11-35.

MENDES, I.A. Investigação histórica no ensino de matemática. Rio de Janeiro: Ciência Moderna Ltda., 2009.

PENTEADO, M. G. Possibilidades para a formação de professores de matemática. In: BORBA, M. de C. (Orgs.). A informática em ação: formação de professores, pesquisa e extensão. São Paulo: Olho d'Água, 2000. p. 23-34.

RODRIGO DUDA - Mestre em Matemática pela Universidade Estadual de Ponta Grossa (UEPG). Professor do Ensino Básico, Técnico e Tecnológico no Instituto Federal do Paraná (IFPR) - Câmpus Irati. E-mail: rodrigo.duda@ifpr.edu.br

SANI DE CARVALHO RUTZ DA SILVA - Doutora em Ciência dos Materiais pela Universidade Federal do Rio Grande do Sul (UFRGS). Docente da Universidade Tecnológica Federal do Paraná (UTFPR) Câmpus Ponta Grossa. Professora do Programa de Pós-Graduação em Ensino de Ciência e Tecnologia - PPGECT - UTFPR-PG. E-mail: sani@utfpr.edu.br

DIEGO DUTRA ZONTINI - Doutor em Matemática Aplicada pela Universidade Federal do Paraná (UFPR). Professor do Ensino Básico, Técnico e Tecnológico no Instituto Federal do Paraná (IFPR) Câmpus Irati. E-mail: diego.zontini@ifpr.edu.br

LUCIANE GROSSI - Doutora em Ciências da Computação e Matemática Computacional pela Universidade de São Paulo (USP). Docente do Departamento de Matemática e Estatística da Universidade Estadual de Ponta Grossa (UEPG). Professora do Programa de PósGraduação Mestrado Profissional em Matemática em Rede Nacional (PROFMAT)/UEPG. E-mail: Igrossi.uepg@gmail.com 